\title{
Subtropical Gothic: New Orleans and Posthuman Supernaturals in The Originals
}

\author{
Verena Bernardi
}

Saarland University, Saarbrücken, Germany

\begin{abstract}
The rise of supernatural creatures throughout different media in the post-2000 era has resulted in a significant change of audiences' perceptions of vampires, werewolves and witches (among others). Traditionally used to reflect human fears, lack of morals or instinct-related insufficiencies, these creatures are no longer fear-inducing monsters. Instead, their depiction tends to adopt human qualities to confront the audience with missteps and downfalls of contemporary societies and politics. This paper analyzes the television series The Originals as a supernatural mirror image of American society, where the different communities' struggles for power and their place in New Orleans becomes a micro-cosmos for the American nation. The setting plays a crucial role in the series, which Gothicizes New Orleans to construct a space in which the characters are shown to operate in a posthuman context. This paper will clarify how the protagonists' posthuman characteristics and their placement in the subtropical landscape of Louisiana uncovers contemporary societal concerns and brings aspects such as Urban Gothic and tropicality closer to the audiences' reality. Ultimately, it is in the capital of the subtropical Deep South of America where the hegemonic discourse and practices of discrimination and spatial separation are reflected and challenged.
\end{abstract}

Keywords: Posthumanism, subtropical Gothic, spatial separation, New Orleans, The Originals 
"... the human is what it is because it includes the non-human"

(Nayar, 2014, p. 2)

"We are all humans, but some of us are just more mortal than others."

(Braidotti, 2013, p. 15)

$\mathrm{I}$

$\mathrm{n}$ the $21^{\text {st }}$ century, vampires have experienced a revived popularity on television unparalleled with other supernatural creatures. Increasingly adopting more humanlike qualities and traits in comparison to their literary debut in the early $1800 \mathrm{~s}$, vampires nowadays only rarely exhibit scary behavior. Instead, they more often than not become the center of romantic attention, especially for contemporary young adult audiences. The television series The Originals (2013-2018) follows this trend. Through the series' implementation of posthuman ideologies, which reject simple binaries such as good and evil, The Originals denies its audience the traditionally common practice of allegorical displacement. No longer are vampires and other supernatural creatures shown to be morally inferior to humans. Rather, the series' supernatural communities mirror contemporary Western society in all its positive and negative aspects. This article explores the ways in which The Originals presents New Orleans as a posthuman Gothic locale. Briefly establishing the city's subtropical Gothic character as well as its relevance in the discussion of space, the study goes on to analyze the connection between monstrosity and the establishment of boundaries to achieve and maintain spatial separation amongst different groups of citizens. I seek to uncover how the subtropical city of New Orleans is constructed as the ideal space to address the discourses of tropicality and Urban Gothic. Both of these concepts put emphasis on the concept of Otherness, realized through posthuman qualities, to juxtapose the fictional characters' experiences with those of humans in the non-fiction world. Special attention will be paid to the Gothicization of New Orleans and its surrounding bayous and their construction as a liminal space in which the characters are shown to operate within the context of posthumanism. ${ }^{1}$

\footnotetext{
${ }^{1}$ An early version of this paper entitled "Southern Fangs: Vampires of Deep America and their Regional Attachment" was first presented at the Tropics of the Imagination conference, Singapore, 6-7 September, 2017.
} 


\section{Contradictions galore: New Orleans and its Gothic character(s)}

The Originals' setting in the American South plays a crucial role in the series' discussion of contemporary societal concerns. As Agnieszka Stasiewicz-Bieńkowska points out in "Exotic Otherlands, Headquarters of Death: Sub-tropical Land- and Cityscapes in The Southern Vampire Mysteries", the effects the Gothic genre has on its audiences strongly relies on "the setting within the Gothic story" (2017, p. 19). In American Gothic, iconic European Gothic structures such as castles and dungeons gave way to the wild nature of the New World (e.g. the frontier in works by Charles Brockden Brown) and old or rundown plantation homes, such as "[a] colonial mansion, a hereditary estate . . . a haunted house" (1892, p.647) in Charlotte Perkins Gilman's "The Yellow Wallpaper". As I have argued, the "American Gothic employed psychological horror to distinctly bring the Gothic not only closer to home but into the home" (2018, p. 29). Ultimately, the genre adjusted the depiction of its protagonists' inner workings to match the wilderness of the world in which they found themselves. The genre of tropical and subtropical Gothic traditionally depicts the tropical world as "synonymous with extravagance and excess [resonating] with sensuality and exoticism, while it is simultaneously riddled with diseases and lurking dangers" (Edwards \& Vasconcelos, 2016, p. 4). The enchanting subtropical vegetation of the American South is hence Gothicized through the narratives of hidden dangers lurking in murky waters, overgrown trees and the remains of structures. Similarly, seemingly ordinary and agreeable characters of the Gothic story often reveal themselves as violent, deviant and unpredictable. The juxtaposition of inner state and outward appearance of the genre's setting and characters resonates with Victoria Amador's description of the American South, particularly Louisiana, as "a complex site of contradictions" (2013, p. 163). Ken Gelder, referring to New Orleans, describes the city as "a powerful, occult site for events - a place in the New World which is nevertheless somehow older and more decadent than Europe, simultaneously 'primitive' and sophisticated, a 'mixture' of all kinds of peoples" (1994, p. 110).

In The Originals, all the above-mentioned characteristics are clearly discernible. The subtropical city and its surrounding bayou are presented to viewers as a place of terror and hidden dangers. A thrilling tourist attraction with a multiethnic flair reveals itself as a supernatural hotspot where vampires, werewolves and witches brutally fight for dominance $-a$ trope reminiscent of the region's turbulent history of political and racial conflicts.

As the capital of the subtropical Deep South of America, New Orleans both reflects and challenges the hegemonic discourse and practices of spatial separation. In recent history, 
the cultural phenomenon of spatial separation in America has regained public attention after Hurricane Katrina and the election of President Trump, and in The Originals finds its expression in the distribution of space in New Orleans as a smaller replica of US society. Edwards and Vasconcelos state, "Gothic tropes and conventions have given, and continue to give, vent to the demonic aspects of individual and collective experiences in the American tropics and configure narrative strategies to articulate national and historical issues that have haunted this region for generations" (2016, p. 9). Following this genre characteristic, the French Quarter and the bayou around New Orleans come to play a particularly significant role in The Originals. In this article, the discussion of space in the series will be foregrounded by the juxtaposition of urban areas and the wilderness as they are the sites of struggles for dominance and superiority in the context of continuous racial discrimination.

The connection between the notion of space and its distribution - especially in relation to human differences, discord and supposed inadequacies - reflects a long tradition in the history of the United States of America. The genre of the American Gothic, allegedly the first literary expression of the settlers' experiences in the New World, has for centuries lent itself as a fertile ground to address the issues of space and belonging. Here, supernatural occurrences and creatures have served to embody social taboos, providing cautionary tales against immoral behavior. As Alan Lloyd-Smith states, "[t]he Puritan consciousness itself ... had established a profoundly 'Gothic' imagination of good and evil, and the perilous human experience" (2004, p. 2). Traditionally used to depict human fears, lack of morals or impulse/instinct-related insufficiencies, vampires (and other fictional supernatural beings) have undergone a continuous makeover since Bram Stoker's influential work Dracula (1897), where the creatures' remaining humanity has come to play an increasingly important role. Erica McCrystal (2017) opens her essay "Coexistence and Hospitality: The Gothic Utopian Vision of True Blood" with the words: "One popular trope of Gothic fiction involves the invasion of a foreign threat that raises awareness to barbarism in the real world" (p. 93). Engaging with this trope, The Originals begins with the return of the ruthless original vampire family, the Mikaelsons, to New Orleans. Simultaneously unknown and familiar, the originals are presented as both the founders of the city and foreign, threatening invaders - an ambiguity that enhances their uncanny Gothic character.

\section{Monstrosity and Boundaries: Who You Are Is Where You'll Live}

In line with contemporary audiences' seemingly unwavering appreciation of the figure of the sympathetic vampire, The Originals depicts its main characters, the vampire siblings 
Klaus, Rebekah and Elijah Mikaelson, ${ }^{2}$ as complex individuals whose two main foci lie in reconquering New Orleans and the protection of their family. As viewers find out through flashbacks, Klaus, Rebekah and Elijah actively participated in building New Orleans and shaping its society in the past. The Mikaelsons soon prove to be more powerful and vicious than humans, witches and werewolves, and they eventually manage to subjugate all other groups to their rule.

Although the series examines questions of domination, subjugation and peaceful coexistence using the example of its supernatural communities, these concepts are not new to humankind. Instead, human history shows that the drawing or maintenance of fictive and real boundaries has occupied us throughout time. As Elaine L. Graham (2002) states in Representations of the Post/Human - Monsters, Aliens and Others in Popular Culture, humans have been concerned with "the blurring of boundaries, a dissolution of the 'ontological hygiene' by which for the past three hundred years Western culture has drawn the fault-lines that separate humans, nature and machine" (p. 11). Happening over the same three hundred years as Graham's account of human behavior, the Mikaelson siblings' existence in the supernatural and cultural hotspot of New Orleans has been preoccupied with the achievement of social hierarchies and the solidification of boundaries. Here, the siblings' endeavor to draw clear lines between spaces and communities reminds us of the history of Louisiana when the state's "boundaries were shifted and redrawn periodically to suit circumstances of empire" (Library of Congress, $p$. 3). Supporting Edwards and Vasconcelos' claim that "In the American tropics ... Gothic figures adapt to their social, cultural and political context" (2016, p. 1), the Mikaelsons eventually enact treaties with different groups, assigning certain parts of New Orleans and its surrounding bayou to each of them.

The notions of space and spatial separation are crucial in The Originals. Boundaries, be they spatial or concerning body and mind, are constantly fought over, reinforced and renegotiated. Graham (2002) states that "skin has been a boundary for the soul, for the self, and simultaneously a beginning to the world" (p. 4). In The Originals, vampires do not only invade their victims' skin with their fangs, but also intrude into their minds when they magically compel them to do their bidding or to forget their involuntary blood donation. Graham continues that the "discourse of monstrosity" has been productive in asserting "the boundaries between humans and almost humans" (2002, p. 12), where

\footnotetext{
${ }^{2}$ The brothers Finn and Kol travel daggered in coffins.
} 
Monsters serve both to mark the fault-lines but also, subversively, to signal the fragility of such boundaries. They are truly 'monstrous' - as in things shown and displayed - in their simultaneous demonstration and destabilization of the demarcations by which cultures have separated nature from artifice, human from non-human, normal from pathological. (2002, p. 12)

In The Originals, monstrosity is a fluid concept. In line with posthumanist ideology's rejection of simple binaries (Nayar, 2012, p. 813-14), the old-fashioned dichotomy of good and evil applies neither to the citizens of New Orleans nor to the city itself. Vampires, witches, werewolves, humans, and even the Big Easy are shown to be good, bad or downright evil, depending not on any inherent qualities, but on the circumstances in which they find themselves. In the series, things are rarely what they seem to be. While the different parties successfully manage to conceal their intentions and plans from one another; similarly, New Orleans and its subtropical wilderness, hide the dangers that lie waiting under the lush vegetation and the artistic surface of the city. Reminiscent of Ken Gelder's description of the Southern states as "simultaneously "primitive" and sophisticated" (1994, p. 110), viewers see beautiful buildings with gingerbread balconies and shotgun houses (Amador, 2013, p. 164) displayed along exuberant streets. Yet beyond the façade, many of these dwellings conceal hidden structures such as walledup rooms, secret pathways, or dungeons like The Garden - a subterranean prison where vampires receive punishment by being bricked into a wall in order to starve/desiccate for several decades. As I have noted elsewhere, "The Originals ... directs its attention to New Orleans as the urban center where the commingling races carry out their fights for dominance in urban Gothic settings such as abandoned churches, dusty attics or back allies" (2018, p. 44). Similarly, the Louisiana subtropical wilderness and nature are portrayed as a space of mystery and secrets. The subtropical weather, for instance, reacts to strong magic and responds with fires, torrential rain and destructive winds to a magical ritual gone awry. Similarly, The Hollow, the most powerful witch on Earth, is reborn out of a hollow tree in the middle of the Louisiana wilderness, showing the Gothic and monstrous side of what usually appears idyllic - at least at first glance.

As these examples demonstrate, the series depicts a locale with a Gothic character that allows for, and encourages, contemplation regarding the difficulty in distinguishing good from evil. Individuals do not distinguish between morally just or unjust behavior. Instead, they draw lines according to kinship, which determines the expression of solidarity or the 
questioning of allegiances. On the personal level, mostly at birth, ${ }^{3}$ individuals are assigned to a certain kin. Resulting from this early "passive" allocation to a certain group, members of a community - be they the Mikaelsons (as a separate category of "Originals"), witches, werewolves, vampires or humans - feel loyalty primarily towards those belonging to their own kind and community. Maintaining and defending this community, and its spatial boundaries, becomes their number one priority, with members going to great lengths to secure their safety and well-being through whatever means necessary. The drawing of boundary lines, or the staking of one's territory, plays a crucial role in terms of both how the different groups see themselves, and how others perceive them. The Mikaelsons, for example, rid the French Quarter of werewolves, whose bite poses a real threat to the siblings' health and survival. They do not see anything amiss with their treatment of the werewolves as long as they protect their family. Referring to works of Southern Gothic by William Faulkner, Punter and Byron state that the genre is concerned with "the lost ideals of a dispossessed Southern aristocracy [...] [and] the continuance of racial hostilities" (2004, p. 117). Lloyd-Smith talks of "distorted figures [...] which had lost their authority but not their power" (2004, p.121). These observations are mirrored in The Originals. Both Marcel and Klaus see themselves as kings over New Orleans. However, while Klaus lost his authority, when, hunted by his father he fled the state, Marcel has to accept the end of his rule upon Klaus's return. What they share in common is that the maintenance of their rule strongly depends on outside factors more than on their personal abilities. Unable or unwilling to end the racial hostilities in New Orleans, they each ban the werewolves to the bayou and treat them like animals. Similarly, they forbid the witches to do magic and essentially turn them into servants. As a result, they reinforce the racist tendencies in the city and create a Gothic atmosphere where everyone needs to be wary of their surroundings in order to survive. Typical of tropical Gothic, viewers, along with the characters of the series, are reminded of momentous events and social transitions through which humanity has lived and continues to live.

New Orleans' history of diverse settlements and the presence of numerous ethnic and cultural groups with vast arrays of customs and traditions, makes the city the perfect terrain through which to delineate societal problems, such as racial discrimination and spatial separation. While humanity has a history of categorizing people into diverse "races" based on such fluid criteria as, for instance, skin color; in The Originals, members of the disparate groups come in all shapes and sizes, with no obvious difference in

\footnotetext{
${ }^{3}$ While humans can only be actively turned into a vampire, there are also individuals who are born as a witch, or werewolf, where the werewolf gene lies dormant until the curse is activated when the individual kills another person.
} 
appearance between humans, vampires, werewolves and witches. To the viewer, it is not immediately recognizable to which group an individual belongs unless they flash fangs, show glowing eyes or cast a spell. Referring to the vampire-themed television series True Blood (2008-2014), Erica McCrystal explains that "all beings on the show share the physical attributes of a human face" which creates "an initial relationship that begins simply through face-to-face interaction" (2017, pp. 99-100). According to Levinas, "[t]he face-to-face is a final and irreducible relation which no concept could cover without the thinker who thinks that concept finding himself forthwith before a new interlocutor; it makes possible the pluralism of society" (1991, p. 291). Similarly, in "Coming Out of the Coffin: The Vampire and Transnationalism in the Twilight and Sookie Stackhouse Series," Deborah Mutch (2011) analyzes the vampires' longstanding ability to blend in with human society. Mutch asserts that the fear vampires induce in their audiences arises because we are unable 'to differentiate 'us' from 'them' and from the similarities between 'us' and 'them': vampires deny us the comfort of neat binaries" (p. 76). Thus, the Gothic atmosphere and feelings of unease and discomfort which audiences experience, are not achieved through the othering of the vampire figure, but rather through its likeness to humans. However, while according to McCrystal (2017) "[s]eeing another who shares a similar face allows for beings to engage in social relationships with that other that revolve around responsibility" (p. 100), individuals in The Originals only feel responsibility towards their own kind and their relationship with the city of New Orleans. One can assume that the supernatural communities draw on the Gothic atmosphere of New Orleans, where Old and New World meet, not just in terms of architecture, but also in terms of life philosophy. In their analysis of tropical Gothic, Edwards and Vasconcelos explain, "Out of the encounter between the Old and the New Worlds, or out of the contrast between the urbanized areas and the hinterland, arose a vision that could both idealize and demonize those lands that lay beyond and hid secrets and mysteries yet to be unraveled" (2016, p. 4). In The Originals, Louisiana's famous credo "laissez les bons temps rouler" also means that festivities, tourist shows and the semi-tropical wilderness conceal traditional practices, disputes, fights and even outright wars between the supernatural groups, and create perfect circumstances in which they can hide in plain sight. The fact that there is no difference in outward appearance between members of different supernatural groups does not allow for sympathy and mercy.

Previously, I have theorised that the state of Louisiana and the city of New Orleans, just like The Originals' main male character Klaus Mikaelson, can be understood as a hybrid (Bernardi, 2018, p. 241), or as a place with several identities. Just as none of the supernatural creatures in the series are simply good or evil, the city has more than one face - as is already implied in its nicknames "The Big Easy" and "The City that Care 
Forgot". Founded as a French colony and passed on to Spanish rule before it was sold to the United States, Louisiana has been called home by various ethnic and cultural groups. The state's history of changing governance is replicated in The Originals, where Klaus Mikaelson and Marcel Gerard rule the city alternately, while facing constant challenges to their authority from other communities.

\section{The Originals and Posthumanism}

Unlike the vampire-themed TV series True Blood, which depicts both its human and nonhuman characters' attempts to achieve "a posthuman Gothic utopia by combatting threats of dissenters and using hospitality to unite beings" (McCrystal, 2017, p. 95), the first three seasons of The Originals shows the society of New Orleans as an array of different species who do not wish to reconcile. Instead, the different communities attempt to maintain boundaries and strive to enhance their own power and rule over the city, even at the cost of displacing or eradicating others. The concepts of displacement and eradication are at the heart of posthuman thinking and, as David Roden states, "posthumanism ... comes in different flavours" $(2014$, p. 20). This can be seen in the discussion of posthumanism in science fiction. Hauskeller, Philbeck and Carbonell explain that "A trajectory can be charted in SF's representation of posthumanist concepts" over the past century. In science fiction films:

early 'posthumans' were monsters in horror films - Frankenstein for example. Later, posthumans and transhumans were villains that challenged human society in one way or another. Even later, posthumans became ambiguous in terms of their status as moral creatures... The most recent incarnations are fantasy figures and heroes.... (2015, p. 4)

They conclude that "[t]his trajectory from monsters to heroes is evidence of a change in social consciousness concerning what we consider acceptable posthuman attributes" (2015, p. 4).

Hence, what our society deems dangerous or deviant underlies a slow but continuous change. For a long time, the posthuman figure has been constructed as a threat to humanity, attempting to subjugate or even eradicate humans. The Originals, however, shows a different side of posthumanist thought. Seemingly ignoring the existence of "posthumans" as defined by Hauskeller et al. (2015), the series creates a mirror-image of contemporary human society, reflecting human missteps and wrongful behavior. Instead of designating one individual/community as morally inferior or vicious, the series 
demonstrates how negative and violent behavior can be caused by exterior circumstances and how individuals and communities respond to these circumstances in different ways at different times. Although the series acknowledges the existence of humans, they play a minor role, rarely demonstrating agency or wielding power, aside from a select few characters who eventually all succumb to supernatural disputes. The series' sets its focus mainly on the supernatural communities, which replicate different social strata of U.S. society and which, as I argue, depict the diversity of contemporary society and the versatility of posthumanism. Here, my analysis follows the approach of Critical Posthumanism. As Rosi Braidotti (2016) explains,

The turn to the posthuman is a response to growing public awareness of fast-moving technological advances and also of contemporary political developments linked to the limitations of economic globalization, the risks associated with the 'war on terror' and global security issues. We are experiencing at present an explosion of scholarship on nonhuman, inhuman and posthuman issues, which elicit elation in equal measure to anxiety and stimulate controversial public debates and cultural representations. (p. 13)

In the sense of Braidotti's definition, the supernatural society of New Orleans is composed of vampires, werewolves and witches who represent disparate posthuman qualities and portray an agglomerate of contemporary societal issues. Their position in the social hierarchy, and the powers they wield, find expression in the space that each community occupies. The series setting in New Orleans, Louisiana, plays a crucial role as the city's and the region's harsh past during times of slavery is widely known.

The Mikaelson siblings, New Orleans royalty, exist in an undead state and can be seen as the epitome of a posthuman existence. They are nearly invincible as they are much stronger than regular vampires, and the few white oak stakes which could have killed them are destroyed throughout the course of the series. When the Mikaelsons arrive at the banks of the Mississippi River in the early seventeen hundreds they have many advantages over the settlers and inhabitants of the region. Not only do they possess superior strength over other supernaturals and over their eventual vampire descendants, but they are also able to draw on seven hundred years of life or "undeath" experiences. Additionally, Klaus's hybrid blood can cure a werewolf bite that is otherwise lethal to vampires, which gives the Mikaelsons an edge over all other supernatural communities. The siblings' ability to use mind-control also facilitates their subjugation of the settlers and inhabitants of what would eventually become known as New Orleans. The realization that 
no one was truly capable of threatening or defeating them ultimately led the Mikalesons to reinvent themselves. Using their ability to compel the people around them, they pretend to be of noble standing and bask in the attention of New Orleans' society.

While humans had mostly been unaware of the Mikaelsons' exceptional nature and the existence of non-human creatures, the subjection of the supernatural communities had regularly met with resistance ${ }^{4}$. The witches of New Orleans, in particular, resort to revolt on more than one occasion. However, the siblings repeatedly prove capable of defending their rule, positioning themselves early on as sole rulers and eventually residing in the Mikaelson Compound in the middle of the French Quarter. Their residency in the oldest and central part of the city allows Klaus, Elijah and Rebekah to send a clear signal that they are the ones making decisions and that others have to abide by their rules if they want to remain in New Orleans. As I mentioned at an earlier point in this essay, The Originals does not portray the supernatural communities' attempts at peaceful coexistence, which Erica McCrystal (2017) sees in her analysis of the Gothic vision of True Blood. In this context, McCrystal views hospitality "as the means toward reconciling traditional disjunctures between humans and other creatures in order to offer a posthuman utopia that still maintains its Gothicity" (p. 95). For McCrystal, the vampires' presence signals the continuous existence of the Gothic in our world, where "[t]he posthuman utopia is achieved through mutualistic, hospitable relationships. Thus, the vampire, though traditionally represented and perceived as a Gothic threat, is required to create a harmonious balance between diverse beings" (p. 106). In contrast, in The Originals, hospitality fulfils the exact opposite function. ${ }^{5}$ The Mikaelsons' hospitality is conditional, and whether or not individuals or whole communities are tolerated in the French Quarter depends strongly on their usefulness (see Bernardi, 2017). The question of whether or not individuals are useful has been raised recurrently in contemporary society, closely following traditional Gothic formulas. Early examples of American Gothic fiction were concerned with the topic of the frontier and the fear of the transgression of boundaries. Similar to the settlers' fears of the wilderness and natives, the twenty-first century has seen a reinforcement of borders to keep unwanted individuals and communities out, while allowing only those who could potentially benefit society to enter. This trend might be illustrated by President Trump's intention to build a wall on the U.S.

\footnotetext{
${ }^{4}$ e.g. Papa Tunde wielded powerful enough magic to pose a threat to the Mikaelsons. However, they were able to defeat his attempt to take over the reign of New Orleans by murdering him.

${ }^{5}$ Exceptions to this rule are few. See e.g. Hayley Marshall assumes the role of what Derrida termed the "host's host" (2000, p. 125) when she grants her werewolf pack sanctuary in Klaus's house against his wishes (see Bernardi, 2017, p. 253).
} 
border with Mexico as well as the "refugee crisis" in Europe, where countries such as Malta or Italy actively prevent rescue ships from entering their ports unless other European countries pledge to host the refugees. Through its creation of a supernatural mirror image of contemporary society, The Originals picks up on the issue of border transgression and reinforcement.

\section{Posthuman Traits and their Role in the Distribution of Power}

For over one hundred years of rule in New Orleans, the Mikaelson siblings have acquired a highly privileged status in the city and decide who gets to reside in the French Quarter or who will be banned to the surrounding bayou. In the early nineteen hundreds, however, they were forced to flee the state of Louisiana when their father Mikael arrives with the aim of killing Klaus, who he considers an abomination due to his hybridity. Thinking that Mikael killed Klaus's protégé Marcel during his attack, the siblings hastily leave the city. However, Marcel recovers and seizes the opportunity to take over New Orleans. He assumes Klaus's position and successfully pursues his goal to rule over both human and supernatural communities. Following the example of his vampire mentor, Marcel grants favors, rights and privileges based on individual's or a community's usefulness to his rule. Consequently, he allows the witches to remain in The Quarter while werewolves are exiled from the city, magically forced to stay in their recognizable wolf form, except for one night at a full moon.

The practice of distributing space in accordance with the needs of those in power strongly resonates with the history of New Orleans. Prior to the introduction of Jim Crow Laws, Louisiana enforced a particular concept of residential segregation that set the state apart from other, especially northern, states. As a considerable part of Louisiana's territory consists of subtropical wetland areas that needed to be drained in order to become habitable, the available space had to be used most efficiently. The limited availability of space led to the development of what would become known as the "backyard pattern" (Spain, 1979, p. 83), where masters housed their most important slaves close to their own residences to ensure their availability. In a similar vein, both Marcel and Klaus keep the witches within the French Quarter. Rosi Braidotti (2016) explains that "[t]he dialectics of otherness is the inner engine of humanist Man's power, who assigns difference on a hierarchical scale as a tool of governance" (p. 68). In the world of The Originals' posthuman Gothic version of New Orleans, Marcel and Klaus follow similar practices to ensure and retain their reign over all other species in the city. They decide over the hierarchical setup of the city's society, ultimately turning New Orleans into a posthuman version of contemporary society where structure and spatiality also relies on decisions 
made by those in power. While werewolves pose a threat to vampires and refuse to share their territory with another predatory species, the witches' use of magic, when controlled by Klaus or Marcel, proves a handy resource in their rule over the city.

In the social structure of The Originals, supernatural communities all display different posthuman qualities. While vampires have superseded their human existence by being dead and alive at the same time ${ }^{6}$ New Orleans witches perform ancestral magic, which relies on the power of their deceased and consecrated witch ancestors. Thus the witches' strength, and ultimately their survival, is linked to the deaths of members of their community, which gives their existence a posthuman edge. Their ability to cross the boundary between life and death - even if only with their magic- makes them dangerous adversaries who Marcel is only able to eventually control with the help of the powerful young witch Davina. ${ }^{7}$ The witches' complete reliance on proximity to their deceased ancestors for performing magic restricts their powers to New Orleans, once again highlighting the city's Gothic heritage where the past and presence continuously intertwine. Furthermore, as the vampires are well aware that the witches would lose their magic if forced to leave New Orleans, they can control and blackmail them into doing their bidding. Reminiscent of the aforementioned backyard pattern, Marcel, and later Klaus, allow the covens to stay in their respective parts of New Orleans, controlling their every move. Forcing the witches to participate in their fight over the city, both vampires display highly strategical thinking and reliance on posthuman powers.

Even more strongly than with the witches, the vampires control and rule the community of werewolves. Although the original Mikaelson siblings are close to invincible, The Originals continues the tradition of depicting werewolves as the main nemesis of vampires. The undead are not immortal and can be killed: by beheading, a stake through the heart, the removal of the heart, via powerful black magic, or werewolf venom. As viewers discover throughout the series, werewolves possess animal-like reflexes and display an almost equal strength to vampires. Their agility, paired with the venom of their bite, make a werewolf an effective weapon against the undead. Consequently, to secure both his own power, and the safety of his people, Marcel orders a witch to place a curse on the Crescent pack that prevents the werewolves from turning into their human form.

\footnotetext{
${ }^{6}$ Unlike in True Blood where vampires are literally dead to the world during day times, vampires in The Originals are "undead" 24/7. Those who are privileged enough to possess so-called daylight rings are able to blend in with human society as they are not restricted to remain indoors during the day.

${ }^{7}$ Davina is able to detect when magic is practiced in New Orleans, which enables Marcel to stop the spell immediately, sometimes at a cost of the witch's life.
} 
Exiling the pack to the bayou and incapacitating them with the curse, Marcel is able to eliminate the challenge that they present to his rule. Forced to leave New Orleans and unable to come back undetected by changing to their human form, the werewolves no longer pose a threat to the vampire community.

Werewolves embody the third and last of the three disparate posthuman qualities in the series. Transcending their human physical existence through their ability to change form - hence to shed their human skin - they ultimately breach the boundary between human and animal. Traditionally, fiction portrayed werewolves as Gothic monsters. According to Rebecca Ann Garcia (2016) "with the notion of disembodiment, the posthuman demonstrates the body being a rhetorical strategy in order to create an effect, such as manipulation" (p. 16). In line with Garcia, Anna Kérchy (2018) explains that posthumanism in Gothic fiction causes the breakdown of the cognitive categories and the ideological boundaries, which shape "our world as we understand it" (p.3), and which results in the audience's inability to rely on conventional strategies to create meaning (p. 4). However, in a series such as The Originals, where human existence is almost completely ignored and supernaturals make up the largest part of contemporary society, these creatures hardly instill fear in the television audience anymore. The audience does not need to attempt to find their human role or importance in the series. Instead, they are provided with a world in which they are unable to distance themselves from the atrocities and unfairness shown in The Originals. Unable to hide behind allegorical displacement, viewers are forced to accept what they see - be it fights for survival or turf wars - as a mirror image of struggles for survival, violent conflicts and acts of injustice tearing apart human societies all around the globe.

\section{Conclusion}

The Originals manages to combine the allure of the vibrant, and at the same time, dangerous nature of New Orleans and the American South. The series' plot is richly infused with topics common in American and tropical Gothic genres and uses the subtropical setting of the city and the wilderness surrounding it to create an undertone of danger and injustice, made evident by practices of discrimination and segregation. The series' use of subtropical Gothic becomes obvious when nature turns against the characters and the lush vegetation of the Louisiana bayou and the beautiful exterior of the French Quarter residences become sites of dangerous rituals and bloody fights and wars. Caroline S. Hau states that tropical Gothic "hold[s] a mirror to the so-called best and brightest, to show what the [world] has come to, who have been the authors of its plight, and why things need to change" (2015, n.p.). Constructing New Orleans and its 
surrounding wilderness as liminal spaces which host horrible deeds and events, The Originals' Gothicization of its settings create a ideal stage for the audience to discover parallels with real life events.

In reference to True Blood, McCrystal (2017) explains that a posthuman utopia connects the future with the past according to the Gothic tradition, where the source of the terror (e.g. vampires) would eventually be accepted as part of society (p. 94). Unlike True Blood, The Originals does not aim to lull its viewers into a potential happy and peaceful coexistence of all creatures on Earth. ${ }^{8}$ Instead, the series uses its plot to create an awareness of the injustices and missteps of contemporary social and political relations. None of the characters or communities are depicted as unambiguously good or evil. Hence, instead of offering its viewers hope for better times, the series blatantly confronts its audience with the harsh reality of contemporary living. I argue that The Originals helps its audience to build an awareness of the dangers of drawing unjust boundaries and rigid categories. In "Forging Posthuman Identities" in Dominic Mitchell's In The Flesh," Maria Alberto (2017) states that much of the "contemporary entertainment landscape" is built on narratives which
are often informed by 'a complex vista of contemporary identity' characterized by feared yet fascinating ontological mutability, and more specifically, Gothic-derived definitions of monstrosity [which] have regained popularity in a global society still struggling to overcome, or even explain, cultural differences and shared tragedies (p. 109).

Along the same lines, Pramod Nayar (2014) speaks of a posthuman "species Gothic" ( $p$. 116), where "we as humans, see our own past as a radical Other, and [refuse] to recognize the Other-which-is-us" (p. 119). Unlike numerous other examples of mainstream television series, The Originals does not follow the same formula where cultural differences are oftentimes presented in the form of a romantically involved couple which needs to overcome an array of obstacles in order to live happily ever after (e.g. Twilight, The Vampire Diaries, etc.). Instead, The Originals depicts a whole society and the struggles of its communities, although the plot is interspersed with romance. Ultimately, with the series' refusal to show its vampires and other supernatural creatures as outsiders, The Originals makes them insiders who are aware of, and experience, the

\footnotetext{
${ }^{8}$ Not unlike The Originals, True Blood also depicts conflicts between the separate communities and makes references to real events in humanity's past (e.g. allusion to vampire concentration camps in Season 7). However, the series' finale ends with individuals from many diverse "races" enjoying Thanksgiving together, offering hope for a better future.
} 
same fears and difficulties humanity faces in the real world. By focusing on the missteps and downfalls of the characters and communities, the series draws links to contemporary society's struggles caused by continuous racism and boundary maintenance - but also climate change, globalization and neoliberal capitalism, each of which would be deserving of their own analysis. With the different groups' struggles for power and their place in the city, the series - in line with the tropical Gothic tradition - creates a supernatural mirrorworld of contemporary human experiences. By using New Orleans as "a microcosm for the American nation" (Bernardi, 2018, p. 260), The Originals exposes the continuously unjust treatment of certain individuals and communities based on arbitrarily chosen categories. 


\section{References}

Alberto, M. (2017). Forging posthuman identities in Dominic Mitchell's In The Flesh. In A. Heise-von-der-Lippe (Ed.), Posthuman Gothic (pp.109-124). Cardiff, Wales: University of Wales Press.

Amador, V. (2013). The gothic Louisiana of Charlaine Harris and Anne Rice. In D. Mutch (Ed.), The Modern Vampire and Human Behavior (pp. 163-176). Basingstoke, England: Palgrave Macmillan

Ball, A. (Producer). (2008). True blood [Television Series]. New York, NY: Home Box Office.

Bernardi, V. (2017). "Come on in!" Home, Hospitality and the Construction of Power in The Originals. In D. Baker et al. (Eds.), Hospitality, Rape and Consent in Vampire Popular Culture (pp.37-52). London, England: Palgrave Macmillan.

Bernardi, V. (2017). "Southern Fangs: Vampires of Deep America and their Regional Attachment". Paper presented at theTropics of the Imagination conference, Singapore, 6-7 September.

Bernardi, V. (2018). Us versus Them, or We? Post-2000 vampiric reflections of family, Home and hospitality in True Blood and The Originals (Doctoral Dissertation, Saarland University, Saarbrücken, Germany). doi:10.22028/D291-2754.

Braidotti, R. (2013). The posthuman. Cambridge, England: Polity Press.

Braidotti. R. (2016). Posthuman critical theory. In D. Banerji \& M.R. Paranjape (Eds.), Critical Posthumanism and Planetary Futures (pp. 13-32). India: Springer.

Derrida, J. (2000). Of hospitality: Anne Dufourmantelle invites Jacques Derrida to respond. (Trans. Rachel Bowlby). Stanford, CA: Stanford University Press.

Edwards, J. D., \& G. Vasconcelas, S. (2016). Introduction: Tropicalizing gothic. In J. Edwards and S. Guardini Vasconcelas (Eds.), Tropical Gothic in Literature and Culture: The Americas (pp. 1-12). New York, NY: Routledge.

Fussell, E., Sastry, N., \& Vanlandingham, M. (2010). Race, socioeconomic status, and return migration to New Orleans after hurricane Katrina. Population and Environment, 31(13), 20-42. www.dx.doi.org/10.1007\%2Fs11111-009-0092-2.

Garcia, R. A. (2016). Coming out of the coffin as the posthuman: Posthuman rhetoric and Harris' Sookie Stackhouse series (M.A. Thesis, California State University, San Bernardino, CA, USA). Retrieved from: https://scholarworks.lib.csusb.edu/etd/400/.

Graham, E. L. (2002). Representations of the post/human-monsters, Aliens and others in popular culture. Manchester, England: Manchester University Press.

Gelder, K. (1994). Reading the vampire. New York, NY: Routledge.

Hau, C. S. (2015). Tropical gothic. The Manila Review, (6). Retrieved from: http://themanilareview.com/issues/view/tropical-gothic. Accessed 23 April 2019.

Hauskeller, M., Philbeck, T. D., \& Carbonell. C.D. (2015). Posthumanism in film and television. In M. Hauskeller, et al. (Eds.), The Palgrave Handbook of posthumanism in film and television (pp.1-7). Basingstoke, England: Palgrave Macmillan Limited. ProQuest Ebook Central. Retrieved from: http://ebookcentral.proquest.com/lib/sulb/detail.action?oclD=4001366. 
Kérchy, A. (Ed.). (2018). "Introduction." In A. Kérchy (Ed.), Posthumanism in fantastic fiction (pp-1-7). Americana ebooks. Retrieved from: http://uir.ulster.ac.uk/39991/1/posthuman-pod.pdf. Accessed 31 Jan. 2019.

Levinas, E. (1991). Totality and infinity: An essay on exteriority. Dordrecht, The Netherlands: Kluwer Academic Publishers.

Library of Congress. (n.d.). Louisiana: European Explorations and the Louisiana Purchase. A Special Presentation from the Geography and Map Division of the Library of Congress (pp. 1-118). Washington, DC: Library of Congress. Retrieved from: http://www.loc.gov/static/collections/louisiana-european-explorations-and-thelouisiana-purchase/images/lapurchase.pdf

Lloyd-Smith, A. (2004). American gothic fiction: An introduction. New York, NY: The Continuum International Publishing Group.

McCrystal, E. (2017). Coexistence and hospitality: The gothic utopian vision of True Blood. In A. Heise-von-der-Lippe (Ed.), Posthuman gothic (pp. 124). Cardiff, Wales: University of Wales Press.

Mutch, D. (2011). Coming Out of the Coffin: The Vampire and Transnationalism in the Twilight and Sookie Stackhouse Series. Critical Survey, 23(2), 75-90. doi: 10.3167/cs.2011.230206.

Fussell, E., Sastry, N., \& Vanlandingham, M. (2010). Race, socioeconomic status, and return migration to New Orleans after hurricane Katrina. Population and Environment, 31(13), 20-42. www.dx.doi.org/10.1007\%2Fs11111-009-0092-2.

Nayar, P.K. (2014). Posthumanism. Cambridge, England: Polity Press.

Nayar, P. K. (2012). A new biological citizenship: Posthumanism in Octavia Butler's Fledgling. Modern Fiction Studies, 58(4), 796-817. doi:10.1353/mfs.2012.0062.

Nayar, P.K. (2014). Posthumanism. Cambridge, England: Polity Press.

Perkins Gilman, C. (1892). The yellow wallpaper. The New England Magazine, 11(5), 647-656. www.nlm.nih.gov/theliteratureofprescription/exhibitionAssets/digitalDocs/The-YellowWall-Paper.pdf. Accessed 22 February 2018.

Plec, J. (Producer). (2013). The Originals [Television Series]. Burbank, CA: The CW Network.

Plec, J. (Producer). (2009). The Vampire Diaries [Television Series]. Burbank, CA: The CW Network.

Punter, D., \& Byron, G. (2004). The Gothic. Malden, MA: Blackwell Publishing.

Roden, D. (2015). Posthuman life: Philosophy at the edge of the human. London, England: Routledge.

Spain, D. (1979). Race relations and residential segregation in New Orleans: Two centuries of paradox. The Annals of the American Academy of Political and Social Science, 441(1), 82-96. doi:10.1177/000271627944100107.

Stasiewicz-Bieńkowska, A. (2017). Exotic Otherlands, Headquarters of Death: Sub-tropical land- and cityscapes in The Southern Vampire Mysteries. eTropic 16(1), 18-20. doi:10.25120/etropic.16.1.2017.3566. Retrieved from: https://journals.jcu.edu.au/etropic/issue/archive

Stoker, B. (1897). Dracula. [Orig. Westminster, UK: Archibald Constable and Company]. Planet eBook, Retrieved from: www.planetebook.com/Dracula.asp. 